\title{
Evaluation of the potential of 9 Nannochloropsis strains for biodiesel production
}

\author{
Yubin Ma ${ }^{1}$, Zhiyao Wang ${ }^{1}$, Changjiang Yu, Yehu Yin, Gongke Zhou* \\ Key Laboratory of Biofuels, Shandong Provincial Key Laboratory of Energy Genetics, Qingdao Institute of Bioenergy and Bioprocess Technology, Chinese Academy of Sciences, \\ Qingdao 266101, China
}

\section{H I G H L I G H T S}

- The potential of 9 Nannochloropsis species for biodiesel production was evaluated.

- Growth rate, biomass accumulation and lipid productivity were investigated.

- Further lipid composition, fatty acid profile and biodiesel property were examined.

- The best strain was Nannochloropsis oceanica IMET1 with highest lipid productivity.

\section{A R T I C L E I N F O}

\section{Article history:}

Received 25 March 2014

Received in revised form 12 June 2014

Accepted 13 June 2014

Available online 20 June 2014

\section{Keywords:}

Biodiesel quality

Fatty acid profiles

Lipid productivity

Nannochloropsis

Microalgae

\begin{abstract}
A B S T R A C T
Nannochloropsis have attracted sustained interest from algal biodiesel researchers due to their high biomass accumulation rate and high lipid content. There are six recognized species in the Nannochloropsis genus that are phylogenetically divided into Nannochloropsis gaditana, Nannochloropsis salina, Nannochloropsis granulata, Nannochloropsis limnetica, Nannochloropsis oceanica and Nannochloropsis oculata. In this study, the potential of 9 Nannochloropsis species from the 6 genus for biodiesel production was evaluated by determining their growth rate, biomass accumulation, lipid productivity, lipid composition, fatty acid profiles and biodiesel properties. The results showed that the best strain was $N$. oceanica IMET1, with lipid productivity of $158.76 \pm 13.83 \mathrm{mg} \mathrm{L}^{-1} \mathrm{day}^{-1}$, TAG production of $1.67 \pm 0.20 \mathrm{~g} / \mathrm{L}$, favorable fatty acid profiles of C16-C18 (56.62 $\pm 1.96 \%)$ as well as suitable biodiesel properties of higher cetane number (54.61 \pm 0.25$)$, lower iodine number $\left(104.85 \pm 2.80 \mathrm{gI}_{2} / 100 \mathrm{~g}\right)$ and relative low cloud point $\left(3.45 \pm 0.50{ }^{\circ} \mathrm{C}\right) . \mathrm{N}$. oceanica IMET1 could be consider as valuable feedstock for microalgal biodiesel production.
\end{abstract}

(c) 2014 Elsevier Ltd. All rights reserved.

\section{Introduction}

With the need to reduce carbon emissions, and the dwindling reserves of easily exploitable fossil fuel, biofuels especially biodiesel have attracted much more attention worldwide in recent years. Microalgae are among the most promising feedstock for biodiesel production due to their ability to produce substantial amount of triacylglycerides (TAG), high growth rate and no compete for land with crops used for food production (Ahmad et al., 2011; Chisti, 2007). However, several challenges need to be tackled to allow commercial production of biodiesel from microalgae. Choice of

\footnotetext{
* Corresponding author. Address: Qingdao Institute of Bioenergy and Bioprocess Technology, Chinese Academy of Sciences, No. 189 Songling Road, Laoshan District, Qingdao 266101, Shandong, China. Tel.: +86 53280662731 ; fax: +86 53280662778.

E-mail address: zhougk@qibebt.ac.cn (G. Zhou).

1 These authors contributed equally to this work.
}

suitable algal strain is the key consideration in microalgal biodiesel production pipeline (Scott et al., 2010).

In screening microalgae strain for biodiesel production, Griffiths and Harrison (2009) suggested that the key criterion for choosing oleaginous algae is lipid productivity. Higher lipid productivity could result in higher biodiesel production in microalgae outdoor large-scale cultivation, and vice versa. Suitable microalgae candidates for biodiesel production require not only high lipid productivity, but also suitable fatty acid composition. Fatty acid composition could significantly influence biodiesel fuel properties including kinematic viscosity, specific gravity, cetane number, cloud point and iodine value (Tan and Lin, 2011; Knothe, 2011; Hoekman et al., 2012). In addition, TAG content in total lipid could significantly influence efficiency of microalgal biodiesel production. Although almost all types of microalgal lipids can be extracted, only TAGs are easily transesterified into biodiesel by traditional methods (Gong and Jiang, 2011). Other types of microalgal lipids such as polar lipid can result in loss of biodiesel production 
due to precipitation and saponification (Balasubramanian and Obbard, 2011; Chen et al., 2012). Besides lipid productivity and fatty acid composition, TAG content is another important consideration in microalgae selection for biodiesel production.

At present, several species of Nannochloropsis have attracted sustained interest from algal biodiesel researchers due to their high biomass accumulation rate, high lipid content (Rodolfi et al., 2009; Doan et al., 2011; Chen et al., 2012; Ma et al., 2013), and their successful cultivation at large scale using natural sunlight by companies such as Solix Biofuels, Aurora Algae, Seambiotic, Hairong Electric Company/Seambiotic and Proviron (Radakovits et al., 2012). There are six recognized species in the Nannochloropsis genus that are phylogenetically divided into Nannochloropsis gaditana, Nannochloropsis salina, Nannochloropsis granulata, Nannochloropsis limnetica, Nannochloropsis oceanica and Nannochloropsis oculata (Vieler et al., 2012; Jinkerson et al., 2013). To our knowledge, no research has been conducted to assess which one is the best feedstock for biodiesel production.

In this study, 9 Nannochloropsis from six recognized species, including $N$. gaditana, $N$. salina, $N$. granulata, $N$. limnetica, $N$. oceanica and $N$. oculata, was selected to evaluate their potential for biodiesel production by assessing their biomass accumulation and lipid production. To investigate the reason of high biomass accumulation, the photosynthesis data (Fv/Fm) of the 9 Nannochloropsis was determined. Fv/Fm, indicating the potential maximum quantum efficiency, can directly reflect the photosynthesis activity of PS II (Li et al., 2010). Furthermore, lipid composition and fatty acid profile as well as biodiesel properties estimated by fatty acid profile such as kinematic viscosity, specific gravity, cetane number, cold flow and oxidative stability were also analyzed. The aim of this study was to identify the best feedstock for microalgal biodiesel production from the 9 species of Nannochloropsis.

\section{Methods}

\subsection{Algal strains and cultivation conditions}

N. oceanica IMET1 was kindly provided by Dr. Feng Chen from The University of Maryland Center for Environmental Science. $N$. oceanica 805 from local water system was kindly provided by Dr. Tianzhong Liu from Qingdao Institute of Bioenergy and Bioprocess Technology, Chinese Academy of Sciences. N. limnetica CCMP505, N. granulata CCMP525, N. gaditana CCMP527, N. oculata CCMP529, N. oceanica CCMP531, N. salina CCMP537 and N. salina CCMP1176 were kindly provided by Dr. Jian Xu from Qingdao Institute of Bioenergy and Bioprocess Technology, Chinese Academy of Sciences. The strain was cultured in seawater except $N$. limnetica CCMP505 in freshwater, supplemented with BG-11 medium under $24 \mathrm{~h}$ cool white fluorescent lights at $80-100 \mu \mathrm{mol}$ photons $\mathrm{m}^{-2} \mathrm{~s}^{-1}$ irradiance.

\subsection{Microalgal growth property}

The 9 Nannochloropsis strains were inoculated to $400 \mathrm{~mL}$ bubble column bioreactor with sterile gas composed of air supplemented with $2 \%(\mathrm{~V} / \mathrm{V}) \mathrm{CO}_{2}$. Aeration was carried out at $80 \mathrm{~mL} / \mathrm{min}$. The microalgae were cultured at $25^{\circ} \mathrm{C}$ under continuous illumination at $100 \mu \mathrm{mol}$ photons $\mathrm{m}^{-2} \mathrm{~s}^{-1}$. After cultured for $0,2,4,6,8,10$, $12,14,16,18,20$ and 22 days, the growth of microalgae cells was estimated by measuring the dry cell weight (DCW). A $10-\mathrm{mL}$ sample was filtered through pre-weighed $5 \mu \mathrm{m}$ microporous filter paper, and washed twice with $10 \mathrm{~mL}$ distilled water to remove adhering inorganic salts. The filter paper was oven-dried overnight at $105^{\circ} \mathrm{C}$. The difference between the final weight and the weight of the paper before filtration was taken as the DCW.
The specific growth rate of each strain was calculated from the slope of the linear regression of time and nature log dry weight in exponential growth phase:

$k=\left(\ln N-\ln N_{0}\right) /\left(t-t_{0}\right)$

where $k\left(\mathrm{~d}^{-1}\right)$ is the specific growth rate in exponential growth phase, $N_{0}$ is dry weight at the beginning of the exponential phase $\left(t_{0}\right)$ and $N$ represents the dry weight at time $(t)$ of the exponential phase.

Doubling time can be calculated based on the specific growth rate:

$T=\operatorname{Ln} 2 / k$

\subsection{In vivo monitoring of $\mathrm{Fv} / \mathrm{Fm}$}

Fv/Fm (potential maximum quantum efficiency) was determined after 15 min of dark adaptation using an imaging pulse amplitude-modulated fluorometer (Imaging PAM; Heinz Walz, Effeltrich, Germany) (Maxwell and Johnson, 2000).

\subsection{Determination of lipid content}

The microalgae cells were harvested after 22 days of cultivation by centrifugation at $4722 \mathrm{~g}$ for $10 \mathrm{~min}$. Cell pellets were lyophilized using a freeze drier (Alpha1-2LD Plus; Martin Christ GmBH, Osterode, Germany). The total lipids contained in the algal cells were extracted with a modified chloroform-methanol-water solvent system (Ma et al., 2013).

\subsection{Lipid composition and fatty acid composition analysis}

Lipid components were analyzed using a thin-layer chromatography (TLC) system (TLC-FID, MK-6, Iatron Laboratories, Inc., Tokyo, Japan) (Fedosov et al., 2011; Chen et al., 2012). Samples were dissolved in chloroform to a concentration of $10 \mathrm{mg} / \mathrm{mL}$, and $2 \mu \mathrm{L}$ of solutions containing lipids was spotted onto Chromarod S-III silica coated quartz rods held in a frame. The rods were developed in a solvent system of benzene:chloroform:acetic acid $(150: 60: 2, v / v / v)$ for the first migration to $7.5 \mathrm{~cm}$, followed by a solution of benzene:hexane $(50: 50, \mathrm{v} / \mathrm{v})$ for the second migration to $10 \mathrm{~cm}$. The rods were dried at $70^{\circ} \mathrm{C}$ for $3 \mathrm{~min}$ before they were scanned in the Iatroscan analyzer, which was operated at a flow rate of $0.16 \mathrm{~L} / \mathrm{min}$ for hydrogen and $2 \mathrm{~L} / \mathrm{min}$ for air. The scan speed was $30 \mathrm{~s}$ per rod. The recorded profiles were analyzed by SIC-480 II program. The individual lipid components were identified by cochromatography with pure standards (sterol ester, SE; fatty acid methyl ester, FAME; triacylglycerol, TAG; diacylglycerol, DAG; phospholipids, PL; purchased from Sigma, St. Louis, MO, USA). The quantities of individual components were estimated from the peak areas of pure standards (Chen et al., 2012).

Methyl esters were generated from the microalgae lipids by heating them in a $2 \% \mathrm{H}_{2} \mathrm{SO}_{4}$-methanol solution at $85{ }^{\circ} \mathrm{C}$ for $2.5 \mathrm{~h}$. Fatty acid methyl esters (FAME) were analyzed by GC using a Varian (Walnut Creek, CA) 450 GC equipped with an FID detector and a Varian capillary column CP-Wax 58 (FFAP) CB $(25 \mathrm{~m} \times 0.25 \mathrm{~mm} \times 0.20 \mu \mathrm{m})$. Carrier gas was nitrogen at $1 \mathrm{~mL} /$ min and the split ratio was 1:30. The oven temperature was initially held at $100{ }^{\circ} \mathrm{C}$ for $2 \mathrm{~min}$, followed by an increase to $250{ }^{\circ} \mathrm{C}$ at $10^{\circ} \mathrm{C} / \mathrm{min}$, which was then held for $8 \mathrm{~min}$. The detection system was equipped with a flame ionization detector (FID) operating at $280^{\circ} \mathrm{C}$. FAME peak identification was carried out by GC-MS (NIST, 2.0) operating in the same conditions as the GC-FID. The relative percentage of the fatty acid was calculated on the basis of the peak area of a fatty acid species to the total peak area of all the fatty acids in the oil sample. 


\subsection{Estimation of biodiesel fuel properties based on FAME profiles}

Biodiesel is a renewable transportation fuel consisting of fatty acid methyl esters (FAME). FAME profiles, especially size distribution and the degree of unsaturation, could significantly influence the physical and chemical properties of biodiesel (Hoekman et al., 2012). At present, many equations based on FAME profiles have been built to predict biodiesel properties (Francisco et al., 2010; Hoekman et al., 2012; Nascimento et al., 2013). Especially, the equations of Hoekman et al. (2012) was widely accepted due to the calculated values by the equation were more close to the measured values (Song et al., 2013). In this study, the equations of Hoekman et al. (2012) were selected to predict the biodiesel properties and detailed calculations are as follows:

Average degree of unsaturation was determined as previous described (Song et al., 2013). The relationships between average degree of unsaturation and biodiesel properties including kinematic viscosity, specific gravity, cloud point, cetane number, and iodine value are as shown in Eqs. (1-5) (Hoekman et al., 2012).

$Y=-0.6316 X+5.2065$

$Y=0.0055 X+0.8726$

$Y=-13.356 X+19.994$

$Y=-6.6684 X+62.876$

$Y=74.373 X+12.71$

\subsection{Statistical analysis}

Data were presented as the mean \pm standard deviation of the mean of triplicate samples. Significant differences between means from the 9 species of Nannochloropsis were determined using oneway analysis of variance followed by Duncan's multiple-range tests, using the SPSS statistical package (version 13.0; SPSS Inc., Chicago, IL, USA) at a significance level of $p<0.05$.

\section{Results and discussion}

\subsection{Growth and lipid accumulation properties}

Lipid productivity is a key criterion for choosing oleaginous algae (Griffiths and Harrison, 2009), which could be calculated by biomass productivity and lipid content. Therefore, biomass and lipid accumulation characteristics of the 9 Nannochloropsis were investigated. The results showed that $N$. oceanica IMET1 exhibited the fastest specific growth rate $\left(0.21 \pm 0.0072 \mathrm{~d}^{-1}\right)$, followed by $N$. oculata CCMP529 $\quad\left(0.20 \pm 0.0042 \mathrm{~d}^{-1}\right), \quad N$. salina CCMP1176 $\left(0.19 \pm 0.0087 \mathrm{~d}^{-1}\right), \quad N . \quad$ salina CCMP537 $\left(0.19 \pm 0.0069 \mathrm{~d}^{-1}\right)$, $N$. gaditana CCMP527 $\left(0.18 \pm 0.0019 \mathrm{~d}^{-1}\right), \quad N$. oceanica 805 $\left(0.17 \pm 0.0042 \mathrm{~d}^{-1}\right), N$. granulata CCMP525 $\left(0.13 \pm 0.0045 \mathrm{~d}^{-1}\right)$ and $N$. oceanica CCMP531 $\left(0.11 \pm 0.0046 \mathrm{~d}^{-1}\right)$, and finally $N$. limnetica CCMP505 showed a relatively low specific growth rate $\left(0.07 \pm 0.0064 \mathrm{~d}^{-1}\right)$ (Table 1$)$. The double time showed the similar tendency with the specific growth rate (Table 1 ).

Biomass productivity was calculated by the cultivation time and final biomass at the end of cultivation. The results showed that $N$. salina CCMP1176 had the highest biomass productivity at $363.10 \pm 9.77 \mathrm{mg} \mathrm{L}^{-1} \mathrm{day}^{-1}$, while $N$. salina CCMP537 (316.18 \pm $4.50 \mathrm{mg} \mathrm{L}^{-1}$ day $\left.^{-1}\right), \quad N$. oceanica IMET1 $\quad\left(300.55 \pm 20.25 \mathrm{mg} \mathrm{L}^{-1}\right.$ day $\left.^{-1}\right)$, N. gaditana CCMP527 (296.41 $\left.\pm 6.62 \mathrm{mg} \mathrm{L}^{-1} \mathrm{day}^{-1}\right)$, N. oceanica $805\left(291.91 \pm 19.93 \mathrm{mg} \mathrm{L}^{-1}\right.$ day $\left.^{-1}\right), \quad$ N. oculata CCMP529 $\left(263.64 \pm 9.09 \mathrm{mg} \mathrm{L}^{-1} \mathrm{day}^{-1}\right), \quad$ N. granulata CCMP525 (216.00 \pm $1.93 \mathrm{mg} \mathrm{L}^{-1}$ day $^{-1}$ ) and $N$. oceanica CCMP531 (186.36 \pm $2.73 \mathrm{mg} \mathrm{L}^{-1}$ day $^{-1}$ ) with lower biomass productivity, and finally $N$. limnetica CCMP505 with the lowest biomass productivity $\left(181.14 \pm 2.38 \mathrm{mg} \mathrm{L}^{-1} \mathrm{day}^{-1}\right)$ (Table 1$)$. The biomass productivity of the 9 Nannochloropsis was not consistent with the specific growth rate and the double time. Although N. salina CCMP1176 showed not highest specific growth rate, its biomass accumulation was constantly increased in 22-day cultivation which may result in its highest biomass productivity (Fig. 1).

As indicated in Fig. 2, Fv/Fm showed the similar tendency with the biomass production except $N$. limnetica CCMP505. For example, similar with the biomass production, the $\mathrm{Fv} / \mathrm{Fm}$ of $N$. salina CCMP1176 and $N$. salina CCMP537 showed higher value at the end of cultivation, while $N$. granulata CCMP525 and $N$. oceanica CCMP531 with lower value. In the 9 Nannochloropsis, only N. limnetica CCMP505 was cultured in fresh water which may result in its strange phenomenon in $\mathrm{Fv} / \mathrm{Fm}$ and biomass production. Microalgae biomass production is directly proportional to the efficiency with which the algal cells assimilate carbon from the atmosphere through photosynthesis (Williams and Laurens, 2010). Photosynthesis efficiency is the deciding factor in microalgae biomass production. In this study, our results were consistent with the previous report.

Lipid productivity was not only in connection with biomass productivity, but also lipid content. Furthermore, lipid content of the 9 Nannochloropsis at the end of 22-day cultivation was analyzed. The results showed $N$. granulata CCMP525 attained the highest lipid content at $60.35 \pm 1.20 \%$, while $N$. salina CCMP1176 showed the lowest at $36.95 \pm 0.91 \%$ (Table 1 ). Compared to $N$. salina CCMP1176, N. oceanica CCMP531, $N$. oceanica IMET1, $N$. oculata CCMP529, $N$. oceanica $805, N$. gaditana CCMP527, N. limnetica CCMP505 and $N$. salina CCMP537 could achieve greater lipid content of $53.20 \pm 0.55 \%$, $52.92 \pm 1.04 \%, \quad 52.10 \pm 0.30 \%, \quad 48.96 \pm 2.25 \%, \quad 44.89 \pm 1.58 \%$, $41.17 \pm 0.35 \%$ and $38.75 \pm 1.67 \%$, respectively (Table 1 ). Compared to the biomass productivity, we found the top biomass producers in the present study did not correspond to the top lipid producers. For example, $N$. salina CCMP1176 and $N$. salina CCMP537 showed the highest biomass productivity, while their lipid contents were lowest. The phenomenon was consistent with the previous report

Table 1

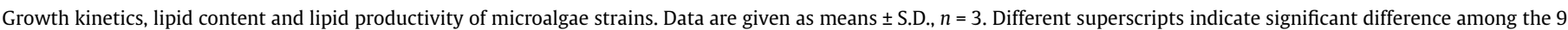
Nannochloropsis species (ANOVA, Duncan's test; $p<0.05$ ).

\begin{tabular}{|c|c|c|c|c|c|}
\hline Strains & $\begin{array}{l}\text { Specific growth } \\
\text { rate }\left(\text { day }^{-1}\right)\end{array}$ & Double time & $\begin{array}{l}\text { Biomass productivity } \\
\left(\mathrm{mg} \mathrm{L}^{-1} \text { day }^{-1}\right)\end{array}$ & $\begin{array}{l}\text { Lipid content } \\
(\%)\end{array}$ & $\begin{array}{l}\text { Lipid productivity } \\
\left(\mathrm{mg} \mathrm{L}^{-1} \text { day }^{-1}\right)\end{array}$ \\
\hline Nannochloropsis oceanica IMET1 & $0.21 \pm 0.0072^{\mathrm{a}}$ & $3.39 \pm 0.12^{\mathrm{a}}$ & $300.55 \pm 20.25^{b}$ & $52.92 \pm 1.04^{\mathrm{b}}$ & $158.76 \pm 13.83^{\mathrm{a}}$ \\
\hline Nannochloropsis oceanica 805 & $0.17 \pm 0.0042^{\mathrm{d}}$ & $4.06 \pm 0.10^{\mathrm{a}}$ & $291.91 \pm 19.93^{b}$ & $48.96 \pm 2.25^{c}$ & $142.92 \pm 16.32^{\mathrm{a}, \mathrm{b}}$ \\
\hline Nannochloropsis limnetica CCMP505 & $0.073 \pm 0.0064^{\mathrm{g}}$ & $9.54 \pm 0.84^{\mathrm{d}}$ & $181.14 \pm 2.38^{\mathrm{e}}$ & $41.17 \pm 0.35^{\mathrm{e}}$ & $74.58 \pm 1.61^{\mathrm{e}}$ \\
\hline Nannochloropsis granulata CCMP525 & $0.13 \pm 0.0045^{\mathrm{e}}$ & $5.21 \pm 0.18^{\mathrm{b}}$ & $216.00 \pm 1.93^{\mathrm{d}}$ & $60.35 \pm 1.20^{\mathrm{a}}$ & $130.36 \pm 3.76^{\mathrm{b}, \mathrm{c}}$ \\
\hline Nannochloropsis gaditana CCMP527 & $0.18 \pm 0.0019^{\mathrm{c}, \mathrm{d}}$ & $3.81 \pm 0.040^{\mathrm{a}}$ & $296.41 \pm 6.62^{b}$ & $44.89 \pm 1.58^{\mathrm{d}}$ & $133.06 \pm 1.72^{\mathrm{b}, \mathrm{c}}$ \\
\hline Nannochloropsis oculata CCMP529 & $0.20 \pm 0.0042^{\mathrm{a}, \mathrm{b}}$ & $3.49 \pm 0.074^{\mathrm{a}}$ & $263.64 \pm 9.09^{c}$ & $52.10 \pm 0.30^{\mathrm{b}}$ & $137.36 \pm 5.53^{b, c}$ \\
\hline Nannochloropsis oceanica CCMP531 & $0.11 \pm 0.0046^{\mathrm{f}}$ & $6.25 \pm 0.26^{\mathrm{c}}$ & $186.36 \pm 2.73^{\mathrm{e}}$ & $53.20 \pm 0.55^{\mathrm{b}}$ & $100.21 \pm 0.43^{\mathrm{d}}$ \\
\hline Nannochloropsis salina CCMP537 & $0.19 \pm 0.0069^{\mathrm{b}, \mathrm{c}}$ & $3.71 \pm 0.14^{\mathrm{a}}$ & $316.18 \pm 4.50^{\mathrm{b}}$ & $38.75 \pm 1.67^{\mathrm{e}, \mathrm{f}}$ & $122.52 \pm 3.53^{c}$ \\
\hline Nannochloropsis salina CCMP1176 & $0.19 \pm 0.0087^{\mathrm{b}, \mathrm{c}}$ & $3.74 \pm 0.18^{a}$ & $363.10 \pm 9.77^{a}$ & $36.95 \pm 0.91^{\mathrm{f}}$ & $134.17 \pm 6.91^{\mathrm{b}, \mathrm{c}}$ \\
\hline
\end{tabular}




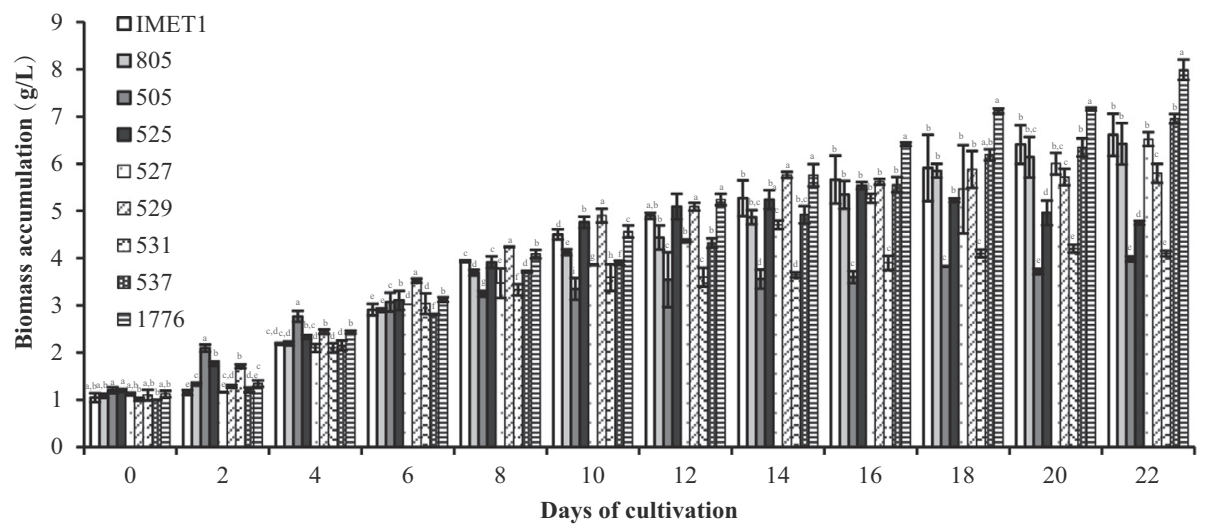

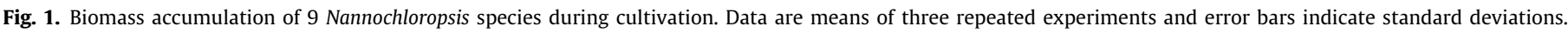
Different superscripts indicate significant difference among the 9 Nannochloropsis species (ANOVA, Duncan's test; $p<0.05$ ).

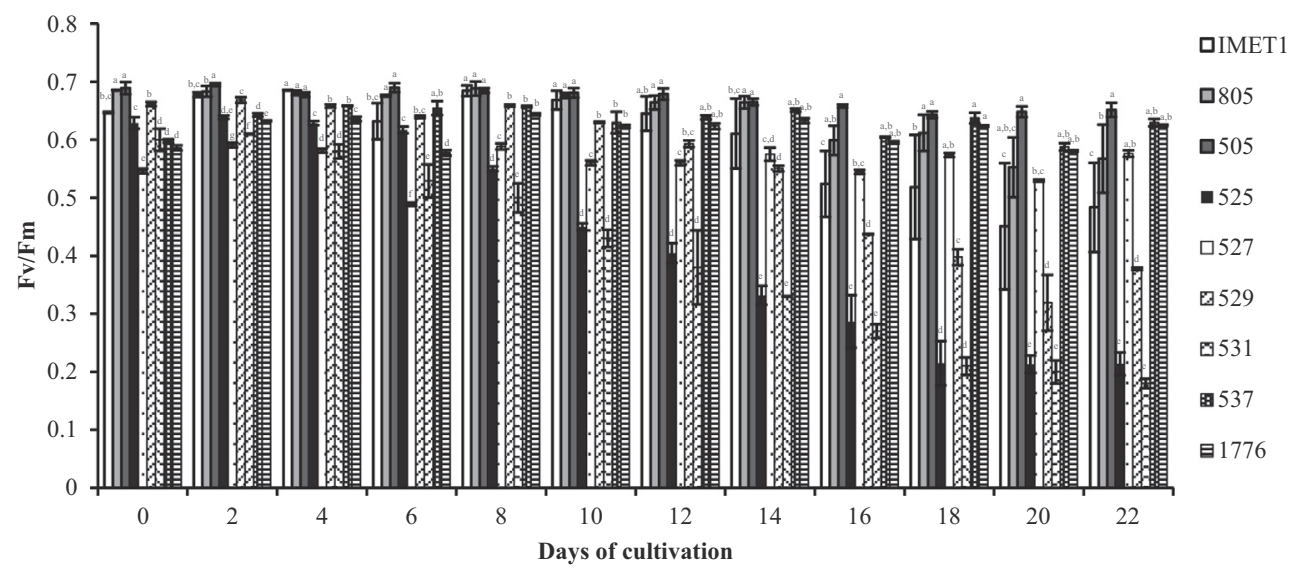

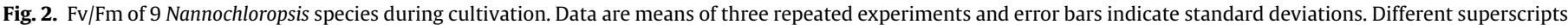
indicate significant difference among the 9 Nannochloropsis species (ANOVA, Duncan's test; $p<0.05$ ).

(Nascimento et al., 2013). Naturally, a strain which has high biomass productivity may manifest in a relative low lipid content and vice versa (Rodolfi et al., 2009).

Combined with the biomass productivity, the lipid productivity of the 9 Nannochloropsis was analyzed. The results showed that lipid productivity of $N$. oceanica IMET1 was the highest $(158.76 \pm$ $\left.13.83 \mathrm{mg} \mathrm{L}^{-1} \mathrm{day}^{-1}\right)$, followed by $N$. oceanica 805 (142.92 \pm $\left.16.32 \mathrm{mg} \mathrm{L}^{-1} \mathrm{day}^{-1}\right), \quad N$. oculata CCMP529 $\left(137.36 \pm 5.53 \mathrm{mg} \mathrm{L}^{-1}\right.$ day $\left.^{-1}\right), \quad N$. salina CCMP1176 $\left(134.17 \pm 6.91 \mathrm{mg} \mathrm{L}^{-1} \mathrm{day}^{-1}\right)$, $N$. gaditana CCMP527 $\left(133.06 \pm 1.72 \mathrm{mg} \mathrm{L}^{-1}\right.$ day $\left.^{-1}\right), N$. granulata CCMP525 (130.36 $\pm 3.76 \mathrm{mg} \mathrm{L}^{-1}$ day $\left.^{-1}\right), \quad$ N. oceanica CCMP537 $\left(122.52 \pm 3.53 \mathrm{mg} \mathrm{L}^{-1}\right.$ day $\left.^{-1}\right)$, and $N$. oceanica CCMP531 (100.21 \pm $\left.0.43 \mathrm{mg} \mathrm{L}^{-1} \mathrm{day}^{-1}\right)$, while $N$. limnetica CCMP505 (74.58 \pm $1.61 \mathrm{mg} \mathrm{L}^{-1} \mathrm{day}^{-1}$ ) was the lowest (Table 1). Based on the lipid productivity, $N$. oceanica IMET1 could be consider as the best feedstock for microalgal biodiesel production in 9 Nannochloropsis.

\subsection{Lipid composition properties}

Besides lipid productivity, lipid composition is another important factor in screening microalgae strain for biodiesel production. To further analyze the lipid characteristics for biodiesel production,

Table 2

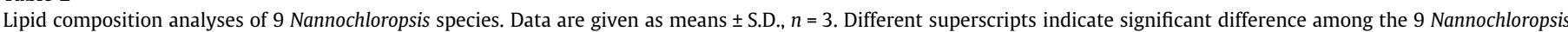
species (ANOVA, Duncan's test; $p<0.05$ ).

\begin{tabular}{|c|c|c|c|c|c|c|c|c|c|}
\hline $\begin{array}{l}\text { Lipid } \\
\text { composition }\end{array}$ & IMET1 & 805 & 505 & 525 & 527 & 529 & 531 & 537 & 1776 \\
\hline $\mathrm{SE}^{\mathrm{A}}$ & $5.43 \pm 3.72^{\mathrm{a}, \mathrm{b}}$ & $3.53 \pm 1.46^{\mathrm{a}, \mathrm{b}}$ & $1.71 \pm 0.1^{\mathrm{b}}$ & $1.99 \pm 0.15^{\mathrm{b}}$ & $3.33 \pm 0.18^{\mathrm{a}, \mathrm{b}}$ & $7.18 \pm 0.15^{\mathrm{a}}$ & $1.60 \pm 0.07^{\mathrm{b}}$ & $1.76 \pm 0.24^{\mathrm{b}}$ & $4.79 \pm 2.78^{\mathrm{a}, \mathrm{b}}$ \\
\hline FAME $^{\text {B }}$ & $6.08 \pm 0.15^{\mathrm{a}, \mathrm{b}}$ & $4.62 \pm 4.59^{\mathrm{a}, \mathrm{b}}$ & $4.97 \pm 0.25^{\mathrm{a}, \mathrm{b}}$ & $9.56 \pm 1.02^{\mathrm{a}}$ & $1.54 \pm 0.054^{\mathrm{b}}$ & $1.79 \pm 0.10^{\mathrm{b}}$ & $2.39 \pm 0.20^{\mathrm{b}}$ & $6.89 \pm 0.99^{\mathrm{a}}$ & $5.38 \pm 5.15^{\mathrm{a}, \mathrm{b}}$ \\
\hline $\mathrm{TAG}^{\mathrm{C}}$ & $47.56 \pm 1.64^{\mathrm{b}, \mathrm{c}}$ & $44.17 \pm 3.90^{\mathrm{c}, \mathrm{d}}$ & $30.85 \pm 1.52^{f}$ & $36.10 \pm 2.00^{\mathrm{e}, \mathrm{f}}$ & $38.24 \pm 3.96^{\mathrm{d}, \mathrm{e}}$ & $54.05 \pm 1.75^{\mathrm{a}, \mathrm{b}}$ & $58.43 \pm 2.00^{\mathrm{a}}$ & $31.38 \pm 2.40^{f}$ & $23.79 \pm 4.63^{g}$ \\
\hline $\mathrm{FS}^{\mathrm{D}} \& \mathrm{DAG}^{\mathrm{E}}$ & $4.53 \pm 2.56^{\mathrm{c}, \mathrm{d}, \mathrm{e}}$ & $2.64 \pm 1.54^{\mathrm{d}, \mathrm{e}}$ & $12.49 \pm 0.91^{\mathrm{a}}$ & $2.63 \pm 0.058^{\mathrm{d}, \mathrm{e}}$ & $9.28 \pm 1.34^{\mathrm{b}}$ & $5.20 \pm 0.56^{\mathrm{c}, \mathrm{d}}$ & $1.50 \pm 0.15^{\mathrm{f}}$ & $7.05 \pm 1.49^{\mathrm{b}, \mathrm{c}}$ & $8.62 \pm 0.65^{\mathrm{b}}$ \\
\hline $\mathrm{PL}^{\mathrm{F}}$ & $36.40 \pm 2.65^{c}$ & $45.05 \pm 5.49^{\mathrm{b}}$ & $49.98 \pm 3.52^{\mathrm{a}, \mathrm{b}}$ & $49.72 \pm 3.52^{\mathrm{a}, \mathrm{b}}$ & $47.60 \pm 5.44^{\mathrm{b}}$ & $31.78 \pm 2.66^{c}$ & $36.10 \pm 2.51^{\mathrm{c}}$ & $52.92 \pm 2.61^{\mathrm{a}, \mathrm{b}}$ & $57.42 \pm 2.91^{\mathrm{a}}$ \\
\hline
\end{tabular}

A SE: percentage of sterol ester (\% of total lipid).

B FAME: percentage of fatty acid methyl ester (\% of total lipid).

C TAG: percentage of triacylglycerol (\% of total lipid).

D FS: percentage of free sterol (\% of total lipid).

E DAG: percentage of diacylglycerol (\% of total lipid)

F PL: percentage of phospholipids (\% of total lipid). 
(a)

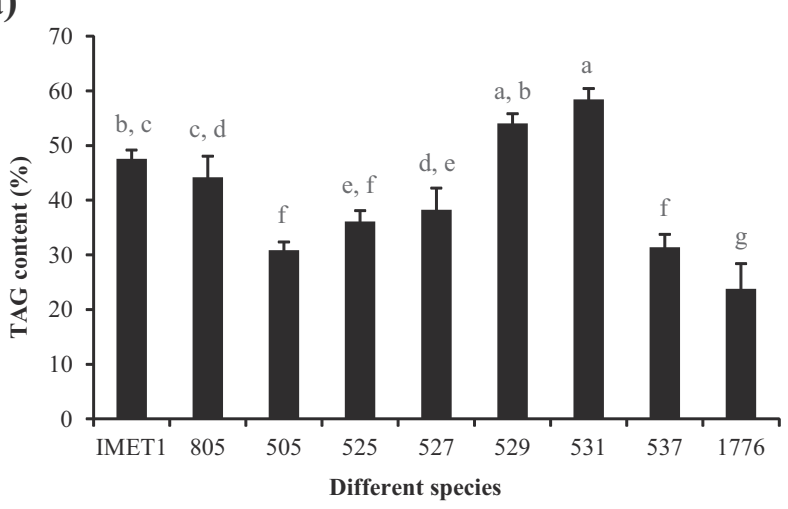

(b)

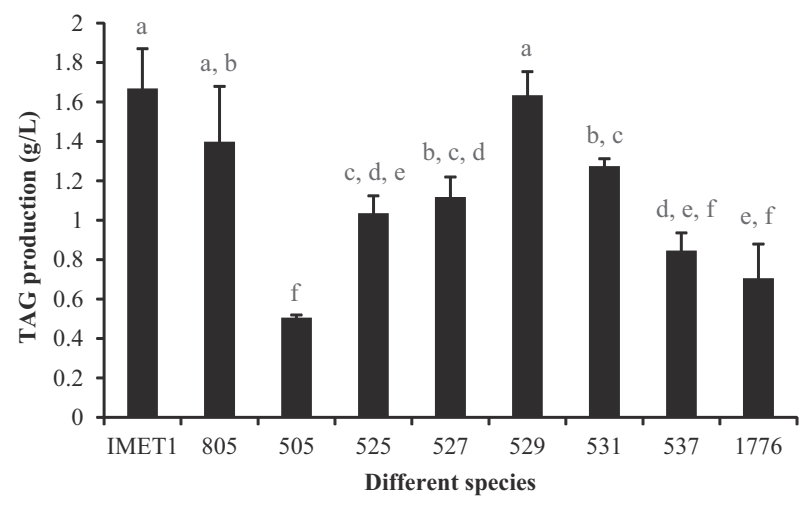

Fig. 3. TAG content (A) and TAG production (B) of 9 Nannochloropsis species. Data are means of three repeated experiments and error bars indicate standard deviations. Different superscripts indicate significant difference among the 9 Nannochloropsis species (ANOVA, Duncan's test; $p<0.05$ ).

the lipid composition of the 9 Nannochloropsis was analyzed. The results showed that polar lipid and TAG were main composition in the total lipid of the 9 Nannochloropsis, while other component contents, including sterol esters (SE), fatty acid methyl ester (FAME), free sterol (FS) and diacylglycerol (DAG) were lower than both TAG and polar lipid content (Table 2). In the all lipid component contents, only TAGs are easily transesterified into biodiesel by traditional methods (Gong and Jiang, 2011). Therefore, TAG content in the total lipid could significantly influence production efficiency of microalgal biodiesel. In this study, TAG content and production of the 9 Nannochloropsis were highlighted. The results showed that the TAG content of $N$. oceanica CCMP531 $(58.43 \pm 2.00 \%)$ and $N$. oculata CCMP529 $(54.05 \pm 1.75 \%)$ was the highest, followed by $N$. oceanica IMET1 (47.56 $\pm 1.64 \%), N$. oceanica 805 (44.17 $\pm 3.90 \%), \quad N$. gaditana CCMP527 (38.24 $\pm 3.96 \%)$, N. granulate CCMP525 $(36.10 \pm 2.00 \%), \quad N$. oceanica CCMP537 $(31.38 \pm 2.40 \%)$ and $N$. limnetica CCMP505 (30.85 $\pm 1.52 \%)$, while N. oceanica CCMP1776 $(23.79 \pm 4.63 \%)$ was the lowest (Fig. 3a). Combined with the lipid production, the TAG production of $N$. oceanica IMET1 was the highest, followed by $N$. oculata CCMP529 and $N$. oceanica 805, while N. oceanica CCMP531, N. gaditana CCMP527, $N$. granulata CCMP525, $N$. oceanica CCMP537, N. oceanica CCMP1176 and $N$. limnetica CCMP505 were relatively lower (Fig. 3b). Based on TAG production, N. oceanica IMET1 showed the highest biodiesel production efficiency in 9 Nannochloropsis.

\subsection{Fatty acid profiles properties}

Ideal microalgae candidates for biodiesel production require not only high lipid and TAG production, but also suitable fatty acid composition. Fatty acid composition of 9 Nannochloropsis was analyzed. The results showed that C16:0 (palmitic acid), C16:1 (palmitoleic acid), C18:1 (oleic acid), C20:4 (eicosatetraenoic acid) and C20:5 (eicosapentaenoic acid) were major fatty acids in 9 Nannochloropsis except $N$. limnetica CCMP505 (Table 3). Compared with other species, $N$. limnetica CCMP505 showed the different fatty acid profile, which may due to its inconsistent cultivation condition in freshwater. When cultivated in seawater, N. limnetica CCMP505 showed the similar fatty acid profile with the other Nannochloropsis (Unpublished results). Further analysis showed saturated fatty acids (SFA) ranged from $21.23 \pm 0.27 \%$ to $50.87 \pm 1.73 \%$, monounsaturated fatty acids (MUFA) ranged from $34.37 \pm 2.08 \%$ to $52.56 \pm 1.24 \%$, while polyunsaturated fatty acids (PUFA) ranged from $6.66 \pm 0.64 \%$ to $41.35 \pm 2.46 \%$ in 9 Nannochloropsis species. Previous study revealed that the most favorable biodiesel would have rather low levels of polyunsaturated fatty acids and low levels of saturated fatty acids to decrease oxidative stability and cold flow problems (Knothe, 2009; Hoekman et al., 2012). Therefore, monounsaturated fatty acids were capable of giving the finest compromise between oxidative stability and cold flow (Knothe, 2009;

Table 3

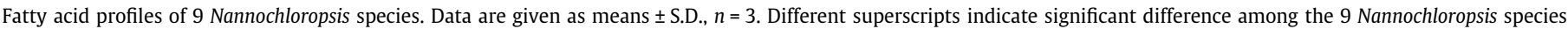
(ANOVA, Duncan's test; $p<0.05$ ).

\begin{tabular}{|c|c|c|c|c|c|c|c|c|c|}
\hline $\begin{array}{l}\text { Fatty } \\
\text { acids }\end{array}$ & IMET1 & 805 & 505 & 525 & 527 & 529 & 531 & 537 & 1776 \\
\hline $14: 0$ & $2.80 \pm 0.26^{\mathrm{c}}$ & $2.86 \pm 0.02^{\mathrm{b}, \mathrm{c}}$ & - & $2.40 \pm 0.03^{c, d}$ & $2.74 \pm 0.31^{\mathrm{c}}$ & $2.07 \pm 0.12^{\mathrm{d}}$ & $4.47 \pm 0.26^{\mathrm{a}}$ & $3.34 \pm 0.19^{b}$ & $2.08 \pm 0.31^{\mathrm{d}}$ \\
\hline $16: 0$ & $27.62 \pm 0.92^{\mathrm{e}}$ & $32.95 \pm 2.36^{\mathrm{c}}$ & $16.64 \pm 0.19^{f}$ & $26.21 \pm 0.92^{\mathrm{e}}$ & $39.19 \pm 1.61^{\mathrm{b}}$ & $29.13 \pm 0.95^{\mathrm{d}, \mathrm{e}}$ & $45.85 \pm 0.92^{\mathrm{a}}$ & $32.23 \pm 0.67^{c}$ & $32.04 \pm 1.80^{\mathrm{c}, \mathrm{d}}$ \\
\hline $16: 1$ & $26.41 \pm 0.27^{\mathrm{a}, \mathrm{b}, \mathrm{c}, \mathrm{d}}$ & $29.36 \pm 4.58^{\mathrm{a}, \mathrm{b}}$ & $2.92 \pm 0.33^{\mathrm{e}}$ & $24.04 \pm 0.64^{\mathrm{d}}$ & $24.14 \pm 1.45^{\mathrm{c}, \mathrm{d}}$ & $28.29 \pm 1.20^{\mathrm{a}, \mathrm{b}}$ & $22.70 \pm 0.27^{d}$ & $25.41 \pm 0.82^{\mathrm{b}, \mathrm{c}, \mathrm{d}}$ & $29.94 \pm 0.85^{\mathrm{a}}$ \\
\hline $16: 2$ & - & - & $3.05 \pm 0.24$ & - & - & - & - & $2.98 \pm 0.95$ & - \\
\hline $18: 0$ & $2.71 \pm 0.05^{\mathrm{b}, \mathrm{c}}$ & $1.90 \pm 0.62^{\mathrm{c}}$ & $4.59 \pm 0.08^{a}$ & $3.25 \pm 0.30^{\mathrm{b}}$ & $3.07 \pm 0.78^{\mathrm{b}}$ & $1.85 \pm 0.15^{c}$ & $0.55 \pm 0.05^{\mathrm{d}}$ & $2.47 \pm 0.70^{\mathrm{b}, \mathrm{c}}$ & $3.19 \pm 0.18^{\mathrm{b}}$ \\
\hline $18: 1$ & $20.82 \pm 0.18^{\mathrm{b}}$ & $22.35 \pm 3.78^{\mathrm{b}}$ & $31.45 \pm 1.75^{\mathrm{a}}$ & $28.52 \pm 0.60^{\mathrm{a}}$ & $14.17 \pm 0.45^{\mathrm{c}}$ & $22.84 \pm 0.85^{\mathrm{b}}$ & $22.15 \pm 0.18^{b}$ & $15.46 \pm 0.71^{\mathrm{c}}$ & $9.37 \pm 0.15^{\mathrm{d}}$ \\
\hline $18: 2$ & $3.80 \pm 0.69^{\mathrm{b}, \mathrm{c}}$ & $2.18 \pm 0.14^{\mathrm{c}, \mathrm{d}}$ & $23.84 \pm 2.12^{\mathrm{a}}$ & $4.71 \pm 0.83^{\mathrm{b}}$ & $2.29 \pm 0.11^{\mathrm{c}, \mathrm{d}}$ & $2.64 \pm 0.12^{\mathrm{c}, \mathrm{d}}$ & $0.72 \pm 0.19^{d}$ & $2.89 \pm 0.29^{\mathrm{b}, \mathrm{c}}$ & $2.58 \pm 0.40^{c, d}$ \\
\hline $18: 3$ & $1.67 \pm 0.12^{\mathrm{b}}$ & $0.91 \pm 0.32^{\mathrm{d}, \mathrm{e}}$ & $17.51 \pm 0.34^{\mathrm{a}}$ & $1.60 \pm 0.10^{\mathrm{b}}$ & $0.96 \pm 0.06^{\mathrm{c}}$ & $1.61 \pm 0.13^{\mathrm{b}}$ & $0.52 \pm 0.12^{\mathrm{e}}$ & $0.65 \pm 0.04^{\mathrm{d}, \mathrm{e}}$ & $0.90 \pm 0.06^{\mathrm{d}, \mathrm{e}}$ \\
\hline $20: 4$ & $6.70 \pm 0.08^{\mathrm{a}, \mathrm{b}}$ & $6.11 \pm 0.80^{\mathrm{a}, \mathrm{b}}$ & - & $4.52 \pm 0.13^{c}$ & $5.81 \pm 0.76^{\mathrm{b}}$ & $6.15 \pm 0.55^{\mathrm{a}, \mathrm{b}}$ & $2.52 \pm 0.08^{\mathrm{d}}$ & $3.64 \pm 0.07^{c, d}$ & $7.16 \pm 0.75^{\mathrm{a}}$ \\
\hline $20: 5$ & $7.45 \pm 0.25^{\mathrm{b}, \mathrm{c}}$ & $8.35 \pm 1.45^{\mathrm{b}}$ & - & $4.74 \pm 0.17^{\mathrm{d}, \mathrm{e}}$ & $7.63 \pm 1.20^{\mathrm{b}, \mathrm{c}}$ & $5.41 \pm 0.32^{\mathrm{c,d}}$ & $2.90 \pm 0.25^{\mathrm{e}}$ & $10.93 \pm 0.14^{\mathrm{a}}$ & $12.74 \pm 1.84^{\mathrm{a}}$ \\
\hline $\mathrm{SFA}^{\mathrm{A}}$ & $33.13 \pm 1.23^{\mathrm{d}, \mathrm{e}}$ & $37.71 \pm 3.00^{c}$ & $21.23 \pm 0.27^{f}$ & $31.86 \pm 1.25^{\mathrm{e}}$ & $45.00 \pm 2.70^{\mathrm{b}}$ & $33.05 \pm 1.22^{\mathrm{d}, \mathrm{e}}$ & $50.87 \pm 1.73^{\mathrm{a}}$ & $38.04 \pm 1.81^{\mathrm{c}}$ & $37.31 \pm 2.29^{c, d}$ \\
\hline MUFA $^{\mathrm{B}}$ & $47.23 \pm 0.45^{\mathrm{a}, \mathrm{b}, \mathrm{c}}$ & $51.71 \pm 8.36^{\mathrm{a}, \mathrm{b}}$ & $34.37 \pm 2.08^{\mathrm{e}}$ & $52.56 \pm 1.24^{\mathrm{a}}$ & $38.31 \pm 1.90^{\mathrm{d}, \mathrm{e}}$ & $51.13 \pm 2.05^{\mathrm{a}, \mathrm{b}}$ & $44.85 \pm 0.45^{\mathrm{b}, \mathrm{c}, \mathrm{d}}$ & $40.87 \pm 1.53^{\mathrm{c}, \mathrm{d}, \mathrm{e}}$ & $39.31 \pm 1.00^{\mathrm{d}, \mathrm{e}}$ \\
\hline PUFA $^{\mathrm{C}}$ & $19.62 \pm 1.14^{\mathrm{b}, \mathrm{c}}$ & $17.55 \pm 2.71^{\mathrm{c}}$ & $41.35 \pm 2.46^{\mathrm{a}}$ & $15.57 \pm 1.23^{c}$ & $16.69 \pm 2.13^{c}$ & $15.81 \pm 1.12^{c}$ & $6.66 \pm 0.64^{\mathrm{d}}$ & $18.11 \pm 0.54^{\mathrm{c}}$ & $23.38 \pm 3.05^{b}$ \\
\hline $\mathrm{UFA}^{\mathrm{D}}$ & $66.85 \pm 1.59^{\mathrm{a}, \mathrm{b}}$ & $69.26 \pm 11.07^{\mathrm{a}, \mathrm{b}}$ & $75.72 \pm 4.54^{\mathrm{a}}$ & $68.13 \pm 2.47^{\mathrm{a}, \mathrm{b}}$ & $55.00 \pm 4.03^{c}$ & $66.94 \pm 3.17^{\mathrm{a}, \mathrm{b}}$ & $51.51 \pm 1.09^{c}$ & $58.98 \pm 2.07^{\mathrm{b}, \mathrm{c}}$ & $62.69 \pm 4.05^{\mathrm{b}, \mathrm{c}}$ \\
\hline
\end{tabular}

A SFA: percentage of saturated fatty acids (\% of total fatty acids).

B MUFA: percentage of monounsaturated fatty acids (\% of total fatty acids).

C PUFA: percentage of polyunsaturated fatty acids (\% of total fatty acids).

D UFA: percentage of unsaturated fatty acids (\% of total fatty acids). 


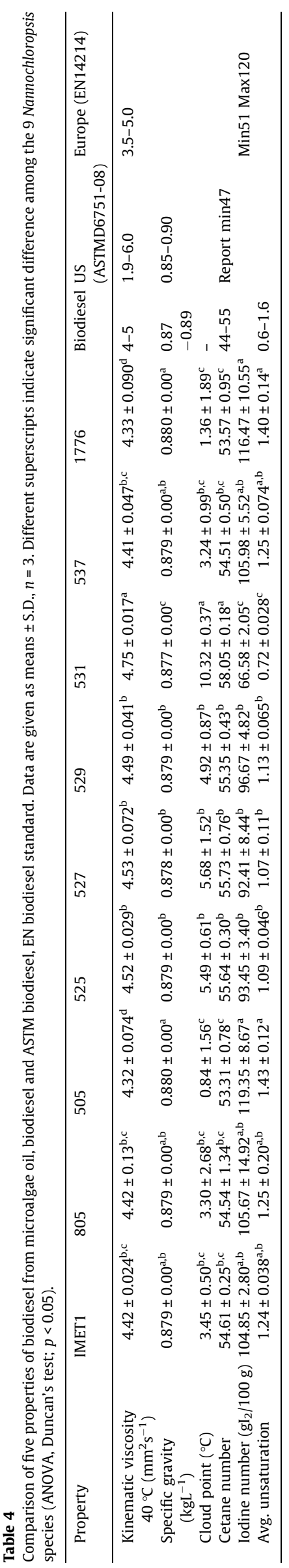

Hoekman et al., 2012). In this study, it was interesting to find that the monounsaturated fatty acids in $N$. oceanica $805, N$. granulata CCMP525 and N. oculata CCMP529 presented a major percentage of approximately $50 \%$, and in other species it had small differences ranging from $34.37 \pm 2.08 \%$ to $47.23 \pm 0.45 \%$.

The consensus view is that the most common feedstocks suitable for biodiesel production were enriched in the five most common C16-C18 fatty acids, including C16:0 (palmitic acid), C18:0 (stearic acid), C18:1 (oleic acid), C18:2 (linoleic acid), and C18:3 (linolenic acid) (Knothe, 2009). The results showed that the 9 Nannochloropsis species possessed considerable amounts of C16 and $\mathrm{C} 18$ species, ranging from $53.70 \pm 2.41 \%$ to $94.03 \pm 4.48 \%$, except for $N$. salina CCMP1176 which contained a substantially low value at $48.08 \pm 2.59 \%$. In addition, polyunsaturated fatty acids appear to be more commonly occurring in the fatty acids of 9 Nannochloropsis species. Several species rich in C20:5 (eicosapentaenoic acid), a functional ingredient showing great benefits to human health (Chen et al., 2013), were N. salina CCMP1176 (12.74 $\pm 1.84 \%)$, N. oceanica CCMP537 (10.93 $\pm 0.14 \%)$ and N. oceanica 805 ( $8.35 \pm 1.45 \%)$. However, it was not suitable for biodiesel production as it would likely result in low oxidative stability. Fatty acid composition could significantly influence biodiesel fuel properties, moreover, due to the diversity and conflicting impacts of fatty acid profiles on biodiesel properties, it is difficult to describe clearly the suitability of fatty acid profiles. Hence, a comprehensive analysis of fatty acid profiles is urgently needed to evaluate biodiesel fuel properties.

\subsection{Estimation of biodiesel's fuel properties of microalgae oils}

As shown in Table 4, five important biodiesel properties besides average degree of unsaturation of the 9 Nannochloropsis species were analyzed. Average degree of unsaturation was proved to have high correlation with several other properties, such as higher average unsaturation leads to lower cetane number and poorer oxidation stability, but improved low temperature performance (Hoekman et al., 2012). Five important biodiesel properties including kinematic viscosity, fuel density, cloud point cetane number and iodine number were estimated based on the relationships built across a range of realistic biodiesel types (Hoekman et al., 2012; Song et al., 2013).

Kinematic viscosity is a measure of resistance to flow of biodiesel (Knothe, 2005). In general, higher viscosity leads to overall poorer combustion, higher emissions, and increased oil dilution. The kinematic viscosity of FAME increases with increasing saturation (Hoekman et al., 2012). The results showed that the estimated kinematic viscosity for microalgal biodiesels was varied from $4.32 \pm 0.074 \mathrm{~mm}^{2} \mathrm{~s}^{-1}$ to $4.75 \pm 0.017 \mathrm{~mm}^{2} \mathrm{~s}^{-1}$ among the 9 Nannochloropsis species. $N$. oceanica CCMP531 showed the highest kinematic viscosity may due to its higher saturated fatty acids content.

Fuel density is a key characteristic that influences engine performance (Hoekman et al., 2012). As fuel injection pumps meter fuel by volume, not by mass, a greater or lesser mass of fuel is injected due to its density. The biodiesel density is affected by average unsaturation (Hoekman et al., 2012). In this study, specific gravity varied within a narrow range of $0.877-0.880 \mathrm{~kg} \mathrm{~L}^{-1}$ for microalgal biodiesels from 9 Nannochloropsis species.

Cloud point is the temperature at which the least soluble biodiesel component crystallizes from solution. Low temperature performance is one of the most important properties for biodiesel. Poor low temperature performance may result in filter plugging due to wax formation, and engine starving due to reduced fuel flow. In general, poor cold flow properties result from the presence of long chain, saturated FAME present in biodiesel (Hoekman et al., 2012). In this study, the results showed that the estimated cloud point for microalgal biodiesels varied among the 9 Nannochloropsis 
species from $1.36 \pm 1.89{ }^{\circ} \mathrm{C}$ to $10.32 \pm 0.37{ }^{\circ} \mathrm{C}$. N . oceanica CCMP531 showed the highest cloud point may due to its higher saturated fatty acids content.

The iodine number is a measure of unsaturation involving the weighted sum of the masses of MUFA and PUFA, important for the biodiesel oxidative stability (Nascimento et al., 2013). High unsaturation levels may result in polymerization of glycerides and formation of deposits (Francisco et al., 2010). The results indicated that $N$. oceanica CCMP531 showed the lowest iodine number $66.58 \pm 2.05 \mathrm{gI}_{2} / 100 \mathrm{~g}$, while $N$. limnetica CCMP505 with the highest iodine number at $119.35 \pm 8.67 \mathrm{gI}_{2} / 100 \mathrm{~g}$.

The cetane number is a dimensionless descriptor related to the ignition quality of a fuel in a diesel engine. Generally, the higher the cetane number, the better the ignition quality of the fuel and vice versa (Knothe, 2009). The cetane number of FAME increases with increasing saturation. In this study, the cetane number varied within a narrow range of $53.31 \pm 0.78-58.05 \pm 0.18$ for microalgal biodiesels from 9 Nannochloropsis species. N. oceanica CCMP531 showed the highest cetane number may due to its higher saturated fatty acids content.

Taken together, according to the two most common quality standards for biodiesel, ASTM D6751 in the US and EN 14214 in Europe, and the ranges of qualities occurring in common biodiesel feedstocks (Hoekman et al., 2012), the values of kinematic viscosity, specific gravity, cetane number and iodine number of the 9 candidates completely satisfied the specifications. There are no definite specifications of cloud point, due to the different climate condition in the United States and Europe (Knothe, 2011). N. oceanica CCMP531 exhibited high cloud point around $10^{\circ} \mathrm{C}$, indicating poor cold flow properties, but they achieved a high cetane number ideal for diesel fuels in terms of combustion (Knothe, 2009). N. oceanica IMET1, the best feedstock for microalgal biodiesel production in 9 Nannochloropsis based on lipid and TAG productivity, also showed favorable biodiesel qualities within the prescribed limits.

\section{Conclusions}

Nannochloropsis has been considered as promising feedstock for microalgal biodiesel production. In this study, 9 Nannochloropsis from six recognized species including $N$. gaditana, $N$. salina, $N$. granulata, $N$. limnetica, $N$. oceanica and $N$. oculata was selected to evaluate their potential for biodiesel production. The best strain was $N$. oceanica IMET1, with lipid productivity of $158.76 \pm 13.83 \mathrm{mg} \mathrm{L}^{-1}$ day $^{-1}$, TAG production of $1.67 \pm 0.20 \mathrm{~g} / \mathrm{L}$, the favorable FA profiles of $\mathrm{C} 16-\mathrm{C} 18$ ( $56.62 \pm 1.96 \%)$ as well as suitable biodiesel properties of higher cetane number $(54.61 \pm 0.25)$, lower iodine number $\left(104.85 \pm 2.80 \mathrm{gI}_{2} / 100 \mathrm{~g}\right)$ and relative low cloud point $\left(3.45 \pm 0.50{ }^{\circ} \mathrm{C}\right)$.

\section{Acknowledgements}

This study was carried out in the framework of QIBEBT-BOEING Joint Research Laboratory for Sustainable Aviation Biofuels Collaboration Agreement, and also supported by the Natural Science Foundation of China (NSFC) (No. 31302163), Natural Science Foundation of Shandong Province (No. ZR2011DQ007), Knowledge Innovation Program of the Chinese Academy of Sciences (No.
KSCX2-EW-Q-22) and CAS/SAFEA International Partnership Program for Creative Research Teams.

\section{References}

Ahmad, A.L., Mat Yasin, N.H., Derek, C.J.C., Lim, J.K., 2011. Microalgae as a sustainable energy source for biodiesel production: a review. Renew. Sustainable Energy Rev. 15, 584-593.

Balasubramanian, R.K., Obbard, J.P., 2011. Heterogeneous catalytic transesterification of phosphatidylcholine. Bioresour. Technol. 102, 1942-1946.

Chen, C.Y., Chen, Y.C., Huang, H.C., Huang, C.C., Lee, W.L., Chang, J.S., 2013. Engineering strategies for enhancing the production of eicosapentaenoic acid (EPA) from an isolated microalga Nannochloropsis oceanica CY2. Bioresour. Technol. 147, 160-167.

Chen, L., Liu, T., Zhang, W., Chen, X.L., Wang, J.F., 2012. Biodiesel production from algae oil high in free fatty acids by two-step catalytic conversion. Bioresour. Technol. 111, 208-214.

Chisti, Y., 2007. Biodiesel from microalgae. Biotechnol. Adv. 25, 294-306.

Doan, T.T.Y., Sivaloganathan, B., Obbard, J.P., 2011. Screening of marine microalgae for biodiesel feedstock. Biomass Bioenergy 35, 2534-2544.

Fedosov, S.N., Brask, J., Xu, X., 2011. Analysis of biodiesel conversion using thin layer chromatography and nonlinear calibration curves. J. Chromatogr. A 1218, $2785-$ 2792.

Francisco, E.C., Neves, D.B., Jacob-Lopes, E., Franco, T.T., 2010. Microalgae feedstock for biodiesel production: carbon dioxide sequestration, lipid production and biofuel quality. J. Chem. Technol. Biotechnol. 85, 395-403.

Gong, Y.M., Jiang, M., 2011. Biodiesel production with microalgae as feedstock: from strains to biodiesel. Biotechnol. Lett. 33, 1269-1284.

Griffiths, M.J., Harrison, S.T.L., 2009. Lipid productivity as a key characteristics for choosing algal species for biodiesel production. J. Appl. Phycol. 21, 493-507.

Hoekman, S.K., Broch, A., Robbins, C., Ceniceros, E., Natarajan, M., 2012. Review of biodiesel composition, properties, and specifications. Renew. Sustainable Energy Rev. 16, 143-169.

Jinkerson, R.E., Radakovits, R., Posewitz, M.C., 2013. Genomic insights from the oleaginous model alga Nannochloropsis gaditana. Bioengineered 4 (1), 37-43.

Knothe, G., 2005. Viscosity of biodiesel. In: Knothe, G., Van, G.J., Krahl, J. (Eds.), The Biodiesel Handbook. AOCS Press, Urbana, pp. 81-83.

Knothe, G., 2009. Improving biodiesel fuel properties by modifying fatty ester composition. Energy Environ. Sci. 2, 759-766.

Knothe, G., 2011. A technical evaluation of biodiesel from vegetable oils vs. algae. Will algae-derived biodiesel perform? Green Chem. 13, 3048-3065.

Li, Y.T., Han, D.X., Hu, G.R., Sommerfeld, M., Hu, Q., 2010. Inhibition of starch synthesis results in overproduction of lipids in Chlamydomonas reinhardtii. Biotechnol. Bioeng. 107 (2), 258-268.

Ma, Y.B., Wang, Z.Y., Zhu, M., Yu, C.J., Cao, Y.P., Zhang, D.Y., Zhou, G.K., 2013. Increased lipid productivity and TAG content in Nannochloropsis by heavy-ion irradiation mutagenesis. Bioresour. Technol. 136, 360-367.

Maxwell, K., Johnson, G.N., 2000. Chlorophyll fluorescence - a practical guide. J. Exp. Bot. 51 (345), 659-668.

Nascimento, I.A., Marques, S.S.I., Cabanelas, I.T.D., Pereira, S.A., Druzian, J.I., Souza, C.O.D., Vich, D.V., Carvalho, G.C.D., Nascimento, M.A., 2013. Screening microalgae strains for biodiesel production: lipid productivity and estimation of fuel quality based on fatty acids profiles as selective criteria. Bioenerg. Res. 6, $1-13$.

Radakovits, R., Jinkerson, R.E., Fuerstenberg, S.I., Tae, H., Settlage, R.E., Boore, J.L., Posewitz, M.C., 2012. Draft genome sequence and genetic transformation of the oleaginous alga Nannochloropsis gaditana. Nat. Commun. 3, 686.

Rodolfi, L., Zittelli, G.C., Bassi, N., Padovani, G., Biondi, N., Bonini, G., Tredici, M.R. 2009. Microalgae for oil: strain selection, induction of lipid synthesis and outdoor mass cultivation in a low-cost photobioreactor. Biotechnol. Bioeng. 102 (1), 100-112.

Scott, S.A., Davey, M.P., Dennis, J.S., Horst, I., Howe, C.J., Lea-Smith, D.J., Smith, A.G. 2010. Biodiesel from algae: challenges and prospects. Curr. Opin. Biotechnol. 21, 227-286.

Song, M.M., Pei, H.Y., Hu, W.R., Ma, G.X., 2013. Evaluation of the potential of 10 microalgal strains for biodiesel production. Bioresour. Technol. 141, 245-251.

Tan, Y.X., Lin, J., 2011. Biomass production and fatty acid profile of a Scenedesmus rubescens-like microalga. Bioresour. Technol. 102, 10131-10135.

Vieler, A., Wu, G.X., Tsai, C.H., Bullard, B. Cornish, A.J., Harvey, C., Reca, I.B., Shiu, S.H., Benning, C., 2012. Genome, functional gene annotation, and nuclear transformation of the heterokont oleaginous alga Nannochloropsis oceanica CCMP1779. PLoS Genet. 8 (11), e1003064.

Williams, P.J.B., Laurens, L.M.L., 2010. Microalgae as biodiesel \& biomass feedstocks: review \& analysis of the biochemistry, energetics \& economics. Energy Environ. Sci. 3, 554-590. 